\title{
Política de ensino para a prevenção da violência: técnicas de ensino que podem contribuir para a diminuição da violência escolar
}

\author{
Alvaro Chrispino*
}

Tais Conceição dos Santos**

\section{Resumo}

0 presente trabalho focaliza o conflito escolar como fruto da massificação da escola, que permitiu o ingresso de estudantes com diferentes origens, valores e culturas, na concretização do direito de uma escola para todos. A manifestação do conflito surge da diferença não trabalhada pela escola. Indica os movimentos realizados no campo das políticas educacionais e os esforços para definir e implantar uma escola pacífica e uma aula pacífica. Apresenta três técnicas de ensino que contribuem para a diminuição da violência escolar com seus fundamentos e possiveis variações.

Palavras chave: Mediação de conflito escolar. Ensino e mediação de conflito. Prevenção da violência escolar.

\section{Teaching policy to violence prevention: Teaching techniques that can contribute to school violence reduction \\ Abstract}

The present work focus on the school conflict as a result of school massification, which allowed the admission of students with different origins, conceptions and cultures. The manifestation of the conflict arises from the distinction the school did not work on. It indicates the movements made in the educational politics field and the efforts to define and implant pacific schools and classes. It presents three teaching techniques that contribute to the school violence reduction with its elements and possible variations.

Keywords: School conflict mediation. Teaching and conflict mediation. School violence prevention.

* Doutor em Educação, Universidade Federal do Rio de Janeiro (UFRJ); Professor dos Programas de Pós-Graduação do CEFET/RJ. E-mail:alvaro.chrispino@gmail.com

** Mestre em Ensino em Biociências e Saúde, Fundação Oswaldo Cruz; Professora do CEFET/RJ. E-mail: thaisquim@hotmail.com 


\section{Política de enseñanza para la prevención de la violencia: técnicas de enseñanza que pueden contribuir para la disminución de la violencia escolar \\ Resumen}

El presente trabajo presenta el conflicto escolar como consecuencia de la masificación de la escuela, entidad que permitió el ingreso de estudiantes de distintos orígenes, valores y culturas, en la práctica del derecho de una escuela para todos. La manifestación del conflicto emerge de la diferencia que existe en la escuela y no se la trabaja. Señala también los movimientos realizados en el área de las políticas educacionales y los esfuerzos para definir e implantar una escuela y una clase pacifica. Presenta tres técnicas de enseñanza que contribuyen para la disminución de la violencia escolar con sus fundamentos y posibles variaciones. Palabras clave: Mediación de conflicto escolar. Enseñanza y mediación de conflicto. Prevención de la violencia escolar.

\section{Introdução}

Existem muitas abordagens possíveis em torno do problema da violência escolar, todas com algum tipo de fundamento e todas respeitáveis. A tese que defendemos, relembramos, é de que estamos despreparados para lidar com a escola de massa e com os antagonismos que surgem na escola atual. A divergência ou diferenças de opinião/valores geram o conflito que, não trabalhado, produz a violência (CHRISPINO; CHRISPINO, 2002; CHRISPINO; DUSI, 2008). Uma importante contribuição nesse sentido vem de Esteve (1995), quando afirma categoricamente:

As relações nas escolas mudaram, tornando-se mais conflituosas, e muitos professores não souberam encontrar novos modelos, mais justos e participativos, de convivência e disciplina. [...]

Nas circunstâncias atuais, um dos aspectos mais importantes da competência social dos docentes é a capacidade de enfrentar situações conflituosas.

Logo, a imaginação e a criatividade poderão produzir um sem-número de ações que permitam intervenção quer no campo da convivência com as divergências (trabalhos para atenuar os preconceitos, habilidade de conviver com o multiculturalismo etc.), quer no campo do antagonismo (habilidade para lidar com idéias e valores contrários etc.) ou mesmo no campo dos conflitos já instalados (mediação de conflito, negociação, arbitragem etc.). Qualquer pessoa que esteja disponível para ouvir e mediar duas posições distintas pode encontrar uma alternativa que seja agradável 
a ambas as partes envolvidas no litígio. Daí, o número de exemplos de aplicação de mediação de conflitos no universo escolar ser bastante amplo.

Até aqui, temos elaborado trabalhos com visões de políticas públicas que se ocupam com apresentar uma explicação possível para as origens da violência escolar que seria causada pelo conflito de opinião, valores e vivência entre os membros da comunidade escolar sem o devido tratamento respeitoso das diferenças (CHRISPINO; CHRISPINO, 2002). Depois, buscamos classificar os conflitos existentes no espaço social como um todo e no universo escolar em especial por acreditarmos que, ao classificarmos os fenômenos, contribuimos para seu melhor entendimento e, assim, favorecemos a busca de políticas efetivas que apresentem soluções construtivas (CHRISPINO, 2007). Após isto, pretendemos identificar a lacuna na formação de professores e gestores nos temas educacionais passiveis de serem enquadrados no Código Civil, no Estatuto da Criança e do Adolescente Código do Consumir, propondo que a escola e seus atores retomem a função de protagonistas nos assuntos - incluindo conflitos de toda ordem - em detrimento da busca de solução nos canais do Poder Judiciário (CHRISPINO; CHRISPINO, 2008). Dando continuidade aos estudos e desenhos de políticas públicas, já propusemos em outros trabalhos uma modelagem de política pública para a redução da violência escolar e promoção da cultura de paz, buscando propor um sistema possivel de interrelações entre os atores políticos e sociais das comunidades que resultasse em ações concretas de redução da violência, propostas a partir de debates com gestores de escolas públicas dos vários níveis de ensino (CHRISPINO; DUSI, 2008). Dos pedidos de aprofundamento que surgem nos diversos encontros com professores e gestores educacionais em torno do tema, dois assuntos são sempre solicitados: o modelo de curso de formação de mediadores do conflito escolar e a apresentação de política de ensino que apresente ações didáticas que permitam que a atividade em sala de aula contribua para a diminuição da violência escolar e dos conflitos de várias ordens, favorecendo a aprendizagem da construção de consensos e a percepção do conflito como algo positivo que, se bem percebido e trabalhado, favorece o bom clima escolar.

Neste momento, buscamos modelar uma política de ensino que apresente um conjunto de atividades para a escola e para a sala de aula e que podem contribuir para o entendimento dos conflitos, para a resolução destes, para transposição das ideias de mediação de conflitos variados para o espaço social mais amplo. Não é nossa pretensão esgotar a discussão sobre as técnicas ou atividades. Pretendemos fazer uma abordagem de politica de ensino sobre conflito escolar para a gestão da sala de aula, a partir do entendimento de que o conflito escolar surge com a massificação da escola e a chegada de alunos diferentes ao mesmo espaço escolar, que essa divergência não é trabalhada pelos responsáveis pela escola por lacuna de formação ou mesmo falta de entendimento sobre a importância do tema, que o conflito natural não trabalhado gera violência e que, por isso, necessitamos de ferramentas que estabeleçam canais de comunicação eficazes a fim de favorecer a vi- 
vência da tolerância. Em função disso, pretendemos responder a pergunta: que técnicas de ensino ou atividades são capazes de contribuir para o entendimento de que somos diferentes e que essa diferença não é ruim? Quais podem contribuir para a aprendizagem do respeito às diferenças e para o exercício da tolerância? Quais favorecem o estabelecimento e/ou manutenção do bom clima escolar?

A busca para as respostas a essas questões deve levar em consideração algumas premissas estratégicas importantes:

1. qualquer que seja a técnica de ensino proposta, ela deve facultar a possibilidade de os alunos anteciparem possiveis acontecimentos conflitivos. 0 exercício de antecipação tem a vantagem de tirar o efeito surpresa do ato gerador de conflito. Ao imaginar o que poderá acontecer, o estudante tenderá a encarar o fato antecipado com maior racionalidade. Aqui, ele antecipa o fato.

2. antecipada a possibilidade, os professores devem simular os possiveis comportamentos e alternativas viáveis para o fato. Enquanto o estudante observa os possíveis cenários futuros, ele é convidado a simular as possiveis alternativas para os diversos atores envolvidos em um exercício de simulação, bem como a dinâmica do desenrolar dos acontecimentos em cada um dos cenários. Aqui, ele imita com perfeição o desenvolvimento dos fatos e suas consequências.

3. E, por fim, após exercitar a antecipação e a simulação, os professores elaboram as possiveis alternativas para cada um dos cenários simulados, estudando o impacto de cada uma delas e suas consequências para os diversos atores envolvidos. Aqui, eles realizam o exercício de escolhas e estudam suas consequências.

Eis, pois, as três premissas estratégicas para uma política de ensino que contribua para a diminuição do conflito envolvendo estudantes e que se utilizará do espaço escolar como palco: antecipar o fato gerador de conflito, simular seus desdobramentos sociais e grupais e considerar as possíveis escolhas. Essas estratégias pretendem diminuir a surpresa ao viver os fatos geradores de conflito e, acima de tudo, dar a perceber aos estudantes que há uma relação direta entre conflitos e escolhas, tanto no surgimento do conflito, quanto no desenvolvimento deste para a manifestação violenta e seu desfecho construtivo.

Os dois primeiros itens estratégicos estão fundamentados nas pesquisas sobre estudos de futuro ou prospectiva (CHRISPINO, 2001a, 2001b, 2009a). 0 terceiro está amparado em pesquisas realizadas por Zehr (2008) com jovens infratores em Nova York. Essas pesquisas, realizadas em diferentes áreas do conhecimento, possuem um ponto em comum sobre o qual gostariamos de fundamentar nossa proposta: a preparação para fazer escolhas consequentes.

Chrispino (2001a, 2001b) aponta a importância da capacidade de antecipar o próprio futuro como uma das competências mais importantes para o sucesso de 
pessoas e nações e apresenta três importantes autores para fundamentar tal proposta: Frederick Polak, Benjamin Singer e Victor Frankl.

Polak (1973) começou a estudar como as nações enxergavam as imagens de seu próprio futuro. Começou a questionar-se se a imagem positiva do futuro era a consequência do sucesso de uma nação ou se o sucesso obtido por determinada nação era a consequência das imagens que alimentava de seu próprio futuro. Estudou como as nações pensavam seu futuro e como se organizavam para concretizar este futuro percebido. Fala da passagem do estágio do sonho para o estágio da visão do futuro e, finalmente, o compartilhamento desta visão com a comunidade visando sua consumação no campo da realidade. Estudou a Grécia, Roma, Espanha, Veneza, Estados Unidos e outros e percebeu que, aqueles que venceram, tinham forte percepção do que queriam ser.

Singer (1974), por sua vez, estudou como o futuro e a imagem do futuro interferiam no sucesso dos alunos. Em sua obra, diz ter percebido que crianças são afetadas pela visão que têm do futuro. Alunos fracos não tem uma visão de futuro além do curto prazo ou do imediato. Alunos com sucesso tem senso pessoal de controle do futuro e pensavam no futuro num prazo de 5 a 10 anos. Estes tinham uma visão bastante profunda e, acima de tudo, positiva sobre seu próprio futuro. Singer defende a ideia do chamado "padrão de gratificação futuro" como algo que leva o aluno ou jovem a investir e acreditar em seu próprio futuro. Frankl (1991), também dedicado a estes estudos, apresenta uma experiência impar. Psiquiatra recolhido aos campos de concentração nazista, buscava encontrar alternativas para manter-se lúcido e vivo. Assim que chegou ao campo de concentração, elegeu para si três princípios: sobreviver, ajudar e tentar aprender. Após a guerra, como sobrevivente, passa a escrever e lega ao mundo uma grande e rica obra literária. Terá, então, a oportunidade de dizer que os que sobreviveram tinham ainda algo a fazer no seu futuro e tinham isto muito claro. Era o cientista com trabalhos importantes inacabados, era o avô que havia feito promessas a seu neto quando da separação pela guerra de extermínio etc. (CHRISPINO, 2001a, p. 46).

As citadas pesquisas parecem indicar que é necessário o exercício de antecipação e que isso facilita a materialização daquilo que se busca. Tal percepção de futuro qualquer que seja ela - pode ser o móvel do sucesso mesmo em condições absolutamente adversas, como exemplifica Frankl (1991). 
Howard Zehr (2008), pioneiro na chamada justiça restaurativa, apresenta interessante pesquisa envolvendo alunos infratores de Nova York e que contribui para melhor entender as diferenças entre alunos da escola de massa. Escreve ele que a linha divisória entre as chamadas classes baixa e média/alta se dá menos em função da educação e da riqueza e mais pelo sentido de escolha e de poder.

0 autor enfatiza que os alunos de classe média e média alta são senhores de seu próprio destino. Apesar do binômio sorte-azar ou de ocorrências aleatórias, esse estrato da população faz escolhas que definem e determinam o futuro, o que reafirma as posições defendidas pelos teóricos da prospecção já citados. Já pessoas da classe desfavorecida não acreditam nisso visto que atribuem os acontecimentos em suas vidas mais ao acaso do que aos atos deliberados que tenham realizado. Se o sucesso Ihes chega, escreve Zehr (2008), é obra do acaso e não de suas escolhas. Se forem presos por algum delito, isso é obra do azar e não por algo que tenham realizado. Para este tipo de grupo, o que chamaremos de sistema azar-sorte responde mais do que o que chamaremos sistema de escolha. É possivel que, para os que se deixam levar pelo sistema azar-sorte, a opção pela violência escolar ou pelo crime seja um exercício explícito de vontade. No delito ou no crime, ele manifesta sua autonomia e seu poder, visto que ele é o protagonista... e não coadjuvante do azar-sorte.

Para ilustrar sua ideia, que ampliamos aqui para o propósito deste trabalho, Zehr lança mão da pesquisa realizada por Parker Rossman (apud ZEHR, 2008, p. 53), que é descrita da seguinte maneira:

Inúmeras pessoas crêem que as coisas Ihes acontecem, não acreditando que suas ações influenciem o futuro. Esta crença tem importantes implicações para a questão de coibir a criminalidade. Para ser coibido é preciso acreditar que suas ações se baseiam em escolhas que, por sua vez, afetam o futuro. Mas as entrevistas que Parker Rossman fez com jovens em conflito com a lei em Nova York oferecem um quadro diferente.

Todos os dias esses jovens vêem pessoas inocentes sendo presas. Todos os dias vêem pessoas culpadas em liberdade. Para eles praticamente não há relação entre delito e punição. Ao contrário, na sua perspectiva a punição é mais ou menos como a chuva que às vezes cai, às vezes não cai: ela molha igualmente os justos e os injustos. A maioria dos jovens têm a expectativa de passar pela experiência de ser pego e punido em algum momento da vida. Como tudo no futuro que enxergam, isto é algo que simplesmente acontece, e que está sob o controle de forças totalmente irresistiveis. 
Pelo que parece, não há uma conexão entre a percepção de futuro e a escolha de vida. Não há relação de causalidade. Por conta disso é que propomos os três eixos estratégicos de políticas públicas para a gestão do ensino, como foco na redução da violência: o exercício de antecipação, o exercício de simulação e o exercício de escolhas.

No esforço de apresentar um contexto escolar que melhor recepcione estas propostas de ensino, vamos apresentar alguns pontos relevantes sobre a escola e aula pacíficas e os enfoques curriculares. Optamos pela abordagem do "maior para o menor", isto é, da escola para a atividade em sala de aula. Esta opção não impossibilita ou invalida a possibilidade de surgimento de atividades voltadas para a redução da violência no espaço da sala de aula e que este movimento contamine as instâncias superiores.

\section{Enfoque da escola pacífica}

A escola pacífica é aquela que se constrói como somatório natural de diversos professores - que exercitam a aula pacífica - e gestores. Ela é alcançada quando a mediação de conflitos deixa de ser uma técnica especialmente estudada no campo cognitivo e ensaiada na ação prática didática, para fazer parte da cultura escolar, que diagnostica o conflito quando ele ainda é um antagonismo e resolve o conflito com o respeito que seus membros exigem, evitando que ele descambe para a manifestação violenta do conflito, que é o que se chama de violência.

Exemplos interessantes deste programa mais amplo são aqueles desenvolvidos, em 1994, pelo San Francisco Peer Resource Programs e pelo The Community Board Program

(HEREDIA, 1999) e que reúnem os seguintes pontos mínimos:

- Um programa de mediação entre pares que trata os conflitos entre estudantes (dimensão horizontal), entre estudantes e adultos (dimensão vertical) e entre adultos (dimensão horizontal);

- Pais que aceitam o programa, utilizam-no em casa e dão apoio sistemático a seus filhos;

- As pessoas ligadas à escola que aceita o programa, usam suas habilidades e princípios, implementam o currículo e dirigem os conflitos fazendo a mediação entre os envolvidos;

- Ensino em sala de aula para todos os estudantes: resolução de conflitos, comunicação eficaz e habilidades de solução de problemas;

- Um programa de mediação de conflitos para adultos que trate de forma efetiva conflitos entre professores, entre professores e pais, etc.

0 chamado enfoque da escola pacifica precisa considerar a necessidade de criar um contexto cooperativo de aprendizagem na instituição de ensino, tais como a descontinuidade de proposta que favoreçam o individualismo e a competição entre 
alunos, como propõem Johnson e Johnson (2004). 0 tema escola pacífica, convivência escolar ou clima são tratado também por lanni (2000), Onetto (2004), Chemen (2006), Míguez (2008), Fierro (2010), dentre outros.

É importante, também, que considerem a necessidade de modificar algumas práticas tradicionais que favorecem o não acolhimento do aluno diferente ou divergente (CHRISPINO; CHRISPINO, 2002). Dentre essas posturas está a inexistência de mecanismos de participação de alunos e pais na determinação de regras gerais, 0 hábito institucional de advertir/suspender/expulsar alunos que não se submetam docemente à norma imposta etc.

A grande diferença entre escolas clássicas e escolas com enfoque pacifista está, certamente, no esforço que estas últimas destinam à implantação de mecanismos de resolução de conflito tais como: a negociação, a mediação entre pares, a mediação por terceiro neutro e a arbitragem. Estas escolas, diferentemente da tradição, buscam mecanismos para transformar a gestão disciplina/indisciplina em processo de reflexão (SCHVARSTEIN, 1999).

\section{Enfoque da aula pacífica}

A abordagem da aula pacífica tem como fundamento um conjunto de procedimentos e dinâmicas de aula que privilegia o aprendizado cooperativo e a prática efetiva dos princípios que contribuem para o desenvolvimento de uma cultura de mediação de conflitos. Heredia (1999) sintetiza esses pontos:

- Cooperação: os estudantes aprendem a trabalhar juntos, a confiar, a ajudar e a compartilhar com os demais;

- Comunicação: os estudantes aprendem a observar cuidadosamente, a comunicar-se com precisão e a escutar com sensibilidade;

- Respeito à diversidade: aprendem a respeitar e a apreciar as diferenças entre as pessoas e a entender o preconceito e como este funciona;

- Exposição positiva das emoções: aprendem a expressar suas emoções e seus sentimentos, especialmente os de ira e de frustração, exprimindo-os de formas não violentas, não agressivas e não destrutivas, exercitando o autocontrole;

- Mediação de conflitos: aprendem as habilidades de responder criativamente e criticamente aos conflitos que ocorrem em seu contexto social mais amplo.

Nesse tipo de aula, o respeito à controvérsia e à diferença é o grande motivador do trabalho didático-pedagógico.

A realização deste tipo de abordagem está também, de alguma forma, relacionada a um contexto cooperativo de aprendizagem ou em outras palavras, a descontinuidade da tradicional valorização de estratégias competitivas ou individualistas e intensificação de estratégias de aprendizagem que atendem ao sucesso coletivo (CABALLERO, 2000). 


\section{Enfoques curriculares}

São, segundo Heredia (1999), conjunto de atividades curriculares com objetivos de produzir conhecimentos, habilidades e atitudes que permitam mudança de comportamento de estudantes em torno do tema conflito, possibilitando maior compreensão, nova postura interpessoal, maior esforço para dominar os instrumentos de comunicação e disposição em buscar soluções pacificas e cooperativas.

Muitos dos programas de redução da violência se propõem a ensinar as técnicas de mediação a todos os alunos, utilizando-se do espaço curricular. Esse procedimento tem a vantagem de educar para a mediação toda a comunidade escolar, transpondo o limiar da técnica de mediação rumo à cultura de mediação. Isto facilita a tarefa dos mediadores no momento de atender a uma manifestação violenta do conflito. A nosso ver, a mediação de conflito é uma tecnologia social que pode se tornar patrimônio do individuo.

É certo que essas inclusões de estudos sobre resolução de conflito precisam cobrir não só o campo teórico, mas também demonstrar a importância da mediação na busca de solução que satisfaça a ambas as partes, como atividades práticas, para que os alunos possam aprender como proceder nas diversas oportunidades em que a história nos ensinou a não transigir, a guerrear e a "não voltar para casa com a desfeita".

Se a teoria sobre a mediação ilumina, a prática a consagra. Podemos dizer que a parte mais teórica se refere à definição, ao surgimento ao desenvolvimento do conflito. Este ponto deve ser estudado como fenômeno inerente à vida humana, que pode redundar em resultados positivos ou negativos, de acordo com a maneira como é conduzido. Os aspectos práticos dizem respeito mais à capacidade de dominar técnicas que auxiliem a entender quando uma situação de conflito se instala e que alternativa de negociação ou mediação é possível.

Esse aspecto do programa se baseia fortemente na premissa de que, se a violência e o preconceito são socialmente aprendidos, a paz, a tolerância, a solidariedade e a mediação também podem sê-lo. E, se isso é verdade - e acreditamos que sim o currículo deve apresentar contribuições para a diminuição de violências escolares como aponta Galvão e outros (2010, p. 417): "a proposta curricular precisa ter como objetivo maior transformar a escola num âmbito de realização pessoal, capaz de transformar padrões de comportamento, produzir ideias, conciliar alternativas e administrar (além de ensinar a administrar) conflitos".

Até aqui, discutiu-se a aplicação de programas específicos sobre mediação de conflito, ampliando um pouco mais as propostas de Heredia (1999). A atividade 
didática geral desenvolvida no conjunto de disciplinas que compõem a grade curricular pode contribuir, sobremaneira, com a cultura da mediação e com a formação dos valores da tolerância e do respeito às diferenças. A maneira como os fatos cotidianos são estudados e mesmo a ênfase dada a aspectos históricos contribuem para acentuar a solução pacífica de acontecimentos conflituosos ou para realçar a solução pela força e pelo uso do poder.

\section{Ações de ensino}

As situações de mediação de conflito na escola podem ser classificadas desde um conflito simples entre dois estudantes em torno de um tema próprio do universo infanto-juvenil até questões mais complexas envolvendo temas sociais ou comunitários que permitem diversas posições controversas. Esse último tipo de mediação pode ser chamada de mediação multiparte. Nató, Querejazu e Carbajal (2006, p. 222) escrevem que esta denominação se refere a

conflitos denominados complexos: os que, por intervenção das autoridades públicas ou por sua repercussão social, não encontram resoluções satisfatórias nos mecanismos institucionais. Envolvem diferentes atores sociais, como organismos governamentais, grupos de vizinhos, empresas, pequenos comerciantes, instituições educativas, de saúde etc. As partes não só são as que estão envolvidas ou afetadas de forma direta pela situação conflitiva, como também os grupos de interesses, os que, mesmo não estando pessoal ou diretamente afetados, tem interesses no assunto a resolver (grupos ecologistas, de direitos humanos, e outros).

Muitos dos fenômenos ou acontecimentos sociais que se desenrolam de forma mais próxima (na comunidade) ou em espaços mais distantes (outro continente), mas que são vividos em tempo real por conta da comunicação, são conflitos multipartes. Eles podem ser indicados e estudados sob a ótica da falsa neutralidade acadêmica ou podem ser observados pela ótica da mediação de conflitos e da cultura de paz, onde se estudam as alternativas para soluções mediadas e não violentas. Deixamos claro que defendemos a ideia de que a mediação como técnica não é valorativamente neutra, como salienta Scharvarstein (1999) e, por isso, preferimos a palavra imparcial (quanto possivel) à neutra.

Gostariamos de propor como ações curriculares efetivas, que podem contribuir para a redução da violência escolar e para a implantação das culturas de mediação e de paz, três técnicas de ensino, a saber: a controvérsia controlada, o uso de dilemas sociais e a dramatização, sendo esta última mais difundida. 


\section{Controvérsia controlada}

A chamada controvérsia controlada, controvérsia simulada ou simulação é um exercício de construção de consenso a partir de debate planejado baseado em posições conflitantes. Aprender a debater ideias discordantes é uma tecnologia social importante para a formação do cidadão. Caballero (2000, p. 104) escrevera que:

Quando se programa o desacordo, quando os alunos têm a oportunidade de exporem as suas opiniões, argumentos e contrastá-los com os de seus companheiros, incentiva-se a curiosidade epistêmica. Em um contexto cooperativo de aprendizagem, esta discordância leva a curiosidade e a busca de novas informações, enquanto que em uma situação competitiva, desacordos, pessoal ou acadêmico, muitas vezes levam ao confronto.

Se os estudantes se acostumam a discutir as suas ideias, opiniões ou conclusões de forma construtiva, se bem programada a atividade, o uso do diálogo será favorecido como uma estratégia fundamental para resolver os seus conflitos.

Flechsig e Schiefelbein (2003) apresentam a ideia de que a origem da técnica de controvérsia está na disputatio, que remonta à Idade Média e consistia em disputas públicas entre os estudantes e também serviam como exames para os exercícios de retórica, visto que era considerado um método de busca pela verdade a partir da argumentação e da contra-argumentação.

Já Johnson e Johnson (2004), numa abordagem mais contemporânea, escreveram que as raízes teóricas da controvérsia estão no desenvolvimento cognitivo, nas teorias do equilíbrio psicológico-social e nas teorias do conflito. Os autores defendem que estas três perspectivas explicam o fato de que os esforços cooperativos da técnica de controvérsia produzem discussões e que estas geram conflitos cognitivos que serão resolvidos no debate orientado. Essa satisfação do conflito - causado pela diferença de percepção/opinião - acarreta uma racionalidade e um novo aprendizado, gerando a reconceitualização sobre o tema em debate. Essa reconceitualização não é, obrigatoriamente, uma modificação da posição anterior. 0 debate não visa a abdicação de posições, mas a oportunidade de apresentar suas ideias e de ouvir a argumentação do outro que pensa/sente diferentemente.

A controvérsia controlada pode ser definida como um método didático de construção de consenso (pelo menos no processo de debate) minuciosamente preparado a partir de regras previamente definidas visando ao exercício de (1) identificação de problemas comuns para fomentar a controvérsia; (2) o exercício de estabelecer padrões mutuamente aceitáveis para sustentar um debate; (3) a busca organizada de informações pertinentes ao tema definido; (4) a preparação da exposição em 
defesa da posição; (5) a capacidade de escutar a posição controversa apresentada racionalmente pelos demais participantes; (6) o exercício de contra-argumentar a partir do conhecimento dos argumentos utilizados pelos demais debatedores e (7) reavaliar as posições - a sua e as demais - a partir de novas informações.

Segundo estes autores

há uma controvérsia acadêmica programada quando as ideias, a informação, as conclusões, as teorias e as opiniões de um aluno se opõem as de outro, mas ambos tratam de chegar a um acordo por meio da proposta de Aristóteles: a discussão das vantagens e desvantagens das ações propostas, apontando para a sintese de novas soluções, a uma resolução criativa do problema (JOHNSON; JOHNSON, 2004, p. 143).

Para Flechsig e Schiefelbein (2003), a técnica de controvérsia apresenta características importantes visto que permite desenvolver metas de aprendizagens e competências específicas: se as demais técnicas em geral pretendem consolidar a chamada "verdade objetiva", que tanto caracterizam o ensino clássico, a técnica de controvérsia busca realçar a argumentação, a apreciação de situações conflitantes, conhecimentos controvertidos, posições diferentes frente a outras e a formação de juízo de valor frente a um tema. As tarefas de aprendizagens para os que desenvolvem a técnica podem ser: elaboração de uma "tese"; a apresentação da "tese"; a identificação de "tese" diferente da sua; a crítica da "tese" diferente a partir de informações e o exercício de síntese. Esse conjunto de atividades resulta no domínio de competências de comunicação e de argumentação importantes para as sociedades atuais.

A partir do que defendem esses autores, podemos estabelecer fases da técnica de controvérsia, e ampliar suas propostas, a saber:

- Fase de preparação, onde se fixam oito aspectos: o que, quando, onde, quem, com quem se deve discutir, quem terá a função de moderador, que tipo de público será convidado e quais são as regras que organizarão o debate;

- Fase de recepção (apresentação das teses): nesta fase será proposta a tese "digna de discussão" que logo deve ser aceita e publicada (difundida);

- Fase de interação (argumentação): os diversos membros dos grupos expõem suas evidências e seus argumentos e, na rodada seguinte, apresentam os contra-argumentos, iniciando a contraposição de idéias;

- Fase de avaliação: aqui, a disputa se resolve com uma decisão do grupo e mesmo com a opinião expressa de possiveis expectadores presentes à disputa ou mesmo um grupo que tenha a função de ser moderador ou decisor da controvérsia. 
A experiência acumulada na elaboração de projetos de controvérsia controlada indica que devemos fugir da posição de contra ou a favor, ou um contra o outro, 0 que poderia lembrar o conhecido "júri simulado", como parecem propor Flechsig e Schiefelbein (2003), A controvérsia controlada é mais rica que o júri simulado porque, primeiro, permite a coexistência no exercício de diversos atores sociais com posições muito distintas e, segundo, não reduz a atividade ao culpado-inocente. A controvérsia controlada faculta posições intermediárias e, mesmo que as posições conflitantes permaneçam, há sempre a oportunidade de ouvir o outro grupo/argumento e debater com eles a partir de fatos e fundamentos.

Para que se cumpram todas as etapas didáticas, o tema a ser utilizado na controvérsia deve combinar a interdependência social com o conflito intelectual, visto que, quanto maior for o número de elementos potencialmente cooperativos e menor o número de elementos competitivos, mais construtivos serão o conflito e a controvérsia. É importante perceber que não é somente o componente cooperativo que contribui para uma controvérsia, mas, também, o componente conflitivo, visto que é este que permitirá a chance de ouvir outras posições e refletir sobre elas.

Johnson e Johnson (2004), ao tratarem das vantagens desta técnica, comparam quatro métodos de ensino: a controvérsia, o debate, o proselitismo e o trabalho individual. Dizem que os estudos experimentais que desenvolveram nos últimos vinte anos permitem concluir que os alunos que participam das controvérsias recordam mais informações corretas, transferem com mais facilidade a aprendizagem a situações novas, empregam estratégias de racionalidade mais complexas e são mais capazes de generalizar os princípios que aprenderam e aplicá-los a um número maior de situações. Dizem que a controvérsia tende a gerar uma visão mais criativa das questões examinadas e mais sinteses permitem combinar as perspectivas em debate. Quando comparado com o debate, a busca de adesão (proselitismo) e trabalho individual, a controvérsia promove mais simpatia, apoio social e autoestima nos participantes do exercício. Os mesmos autores escrevem que

A controvérsia programada é sumamente promissora do ponto de vista didático. Nela encontramos os quatro elementos essenciais: teoria (Johnson, 1970), investigações validadoras, integração nos procedimentos pedagógicos e formação permanente de docentes. A controvérsia programada se baseia no emprego da cooperação para ensinar, e integra o manejo construtivo dos conflitos nas experiências cotidianas de aprendizagem. A medida que os alunos adquirem pericia na resolução de conflitos intelectuais, vai se construindo o cenário para que aprendam a manejar conflitos de interesses entre eles e seus companheiros (JOHNSON; JOHNSON, 2004, p. 150). 
Com outros objetivos, mas utilizando-se do mesmo principio didático, Lipman, Sharp e Oscanyan (1992) propõem a controvérsia controlada como técnica de aprendizagem no projeto de ensino de filosofia para crianças.

0 Education Resources Information Center (ERIC) possui um grande arquivo de texto e experiências acadêmicas sobre controvérsias acadêmicas em diversas áreas e niveis de educação. Uma pesquisa realizada n Search the Thesaurus, com a expressão Controversial Issues resulta em 1.698 itens das mais diversas áreas do conhecimento.

Temos, de nossa parte, estudado a técnica da controvérsia controlada como alternativa para ensinar aos alunos que a sociedade é formada por visões diferentes, e que o fato de serem diferentes não os fazem errados ou adversários, como propõe a Abordagem CTS-Ciência, Tecnologia e Sociedade (CHRISPINO, 2009b, 2005; REIS, 2008; CARVALHO et al., 2006; FARIAS; CARVALHO, 2007). Esta técnica também foi proposta como alternativa para a resolução de conflitos por Johnson e Johnson (2004) e por Cabalerro (2000).

\section{Dilemas}

Segundo a filosofia "dilema é uma situação embaraçosa em que nos encontramos, devendo escolher necessariamente entre dois pontos de vista rejeitáveis caso não fôssemos obrigados a escolher" (JAPIASSÚ; MARCONDES, 1996). Os autores apresentam o exemplo do cirurgião que, não podendo salvar mãe e filho no momento do parto precisa escolher entre um deles. Para Mora (1993), dilema "é a oposição de duas teses, de tal modo que, se uma delas é verdadeira, a outra terá de ser considerada falsa, e vice-versa".

No campo das ciências sociais e na teoria dos jogos, os dilemas têm sido usados para estudar o problema da relação/cooperação entre indivíduos, grupos e nações em diversos tipos de problemas. Essa característica dos dilemas é que nos permite indicá-la como técnica capaz de contribuir com a cultura da mediação de conflito. Myers (2000, p. 281-282), ao estudar os dilemas, escreve:

Os problemas que mais ameaçam o futuro da humanidade - armamentos nucleares, aquecimento global, superpopulação, esgotamento dos recursos naturais - surgem na medida em que as várias partes visam a interesses particulares, em detrimento do interesse coletivo.

A fim de isolar e ilustrar [o] dilema, os psicólogos sociais têm empregado jogos de laboratório que revelam a essência de muitos conflitos sociais reais. Ao nos mostrar como pessoas bem-intencionadas são envolvidas em comportamentos mutuamente destrutivos, eles focalizam alguns paradoxos fascinantes, embora perturbadores, da existência humana. 
Existem alguns dilemas muito difundidos e, dentre eles, gostaríamos de elencar três: o Dilema do Prisioneiro, a Tragédia dos Comuns e o Dilema de Heinz.

0 Dilema do Prisioneiro parece derivar da história de dois suspeitos interrogados em separado pelo Promotor de Justiça responsável pelo caso. Sabedor que ambos os presos eram culpados, e que só seria, condenados como por crimes de menor gravidade, o Promotor busca incentivar os acusados a colaborarem na solução do caso. Oferece benefícios àquele que cooperar, incriminando o outro.

Vejamos como pode ser resumido o Dilema do Prisioneiro, a partir de uma das muitas versões deste dilema: Dois suspeitos, A e B são presos pela polícia. A Promotoria tem provas insuficientes para condená-los a crimes de maior gravidade, mas, separando os prisioneiros A e B, oferece a ambos o mesmo acordo:

1. Se um dos prisioneiros, confessando, testemunhar contra o outro, e esse outro permanecer em silêncio, o que confessou sai livre, enquanto o cúmplice silencioso cumpre 10 anos de sentença.

2. Se ambos ficarem em silêncio, a polícia só pode condená-los a um ano de cadeia cada um.

3. Se ambos traírem o comparsa, cada um leva cinco anos de cadeia.

Frente às possibilidades apresentadas, cada prisioneiro faz a sua decisão sem saber a decisão do outro, e nenhum tem certeza ou é informado sobre a decisão do outro. Dependendo da decisão e do tempo em que ela é tomada, o prisioneiro pode receber a liberdade, ou pegar 1, 5 ou 10 anos de pena. A questão que o dilema propõe é: o que vai acontecer? Que decisão tomar?

A tabela a seguir resume as possibilidades de cada prisioneiro frente às opções de escolha:

Tabela 1 - Possibilidades de escolha.

\begin{tabular}{l|l|l|l}
\hline Matriz do & \multicolumn{2}{|l}{ Prisioneiro "B" } \\
\cline { 2 - 4 } Dilema do Prisioneiro & Não confessa & Confessa \\
\hline \multirow{2}{*}{ Prisioneiro "A" } & Não confessa & $\begin{array}{l}\text { Ambos são condenados } \\
\text { a 1 ano }\end{array}$ & $\begin{array}{l}\text { "B" está livre; "A" é } \\
\text { condenado a 10 anos; }\end{array}$ \\
\cline { 2 - 4 } & confessa & $\begin{array}{l}\text { "A" está livre; "B" é } \\
\text { condenado a 10 anos }\end{array}$ & Condenado a cinco anos \\
\hline
\end{tabular}

Fonte: Os autores (2010). 
Utilizando uma classificação de ganha-ganha, ganha-perde e perde-perde, teremos que a mesma tabela pode ser representada da seguinte forma:

Tabela 2 - Possibilidades de escolha na visão perde-ganha.

\begin{tabular}{l|l|l}
\hline & Confessa & Não confessa \\
\hline Confessa & ganha - ganha & $\begin{array}{l}\text { perda substancial } \\
- \text { ganho substancial }\end{array}$ \\
\hline Não confessa & $\begin{array}{l}\text { ganho substancial } \\
\text { - perda substancial }\end{array}$ & perda - perda \\
\hline
\end{tabular}

Fonte: Os autores (2010).

A derivação do Dilema do Prisioneiro é sempre aplicada, por exemplo, na corrida armamentista. Dois chefes de Estado em tratativas para um acordo de desarmamento têm duas opções: ou incrementar os gastos militares, ou chegar a um acordo para reduzir o seu armamento. Nenhum dos dois Estados pode garantir que o outro cumprirá o acordo. Em geral, ambos se tendem para a manutenção de seu status militar.

Myers (2000) salienta que muitos dilemas sociais envolvem mais de duas partes, como o efeito estufa, que deriva do desmatamento desregrado, da emissão de gás carbônico dos automóveis, dos fogões e usinas termelétricas. A participação é individual e o prejuizo é coletivo. Para estes casos, os pesquisadores sociais desenvolveram modelos de dilema para laboratórios que envolvem múltiplos atores.

0 Dilema da "Tragédia dos Comuns" é utilizado para modelar tais situações, conforme nos apresenta Myers (2000, p. 283):

Uma metáfora para a natureza insidiosa dos dilemas sociais é o que o ecologista Garrett Hardin (1968) chamou de a "tragédia dos comuns". Ele tirou o nome de commons, termo que designava a área de pastagem situada no centro das antigas cidades inglesas, mas "comuns" pode designar qualquer outro recurso que é partilhado, como por exemplo o ar, a água, os peixes etc. Se todos usarem o recurso com moderação, é possível renová-lo com a mesma velocidade com que é consumido. A relva vai crescer no pasto e os peixes vão se reproduzir. Se os recursos forem usados indiscriminadamente, ocorrerá uma tragédia dos comuns. Imagine 100 fazendeiros em tomo de uma pastagem comum capaz de alimentar 100 vacas. Quando cada um leva uma vaca para lá, o pasto comum é usado otimizadamente. Mas depois alguém raciocina: "Se eu puser uma segunda vaca no pasto, dobrarei a minha produção, com apenas 1 por cento a mais no consumo do pasto." Assim, esse fazendeiro acrescenta uma segunda vaca. 0 mesmo fazem os 
outros fazendeiros. 0 resultado inevitável? A Tragédia dos Comuns [...] um campo lamacento e sem pasto.

Para evitar a "tragédia dos comuns", é possivel vislumbrar duas opções para o uso não planejado de recursos finitos: ou o Estado cria mecanismos legais para regular determinadas práticas ou a própria sociedade cria mecanismos de autoregulação e defesa. Para ambos os casos, precisamos de cidadãos educados para 0 exercício de cobrança do Estado e para a organização social.

Após estas primeiras reflexões em torno dos Dilemas do Prisioneiro e da Tragédia dos Comuns, vamos estudar o conhecido Dilema de Heinz, foi apresentado por Lawrence Kohlberg (1927-1987) para interessante discussão sobre o julgamento moral.

0 Dilema de Heinz pode ser apresentado da seguinte maneira: em uma determinada cidade da Europa, uma mulher estava com câncer. Um farmacêutico da mesma cidade descobriu um medicamento capaz de salvar-lhe a vida. 0 desenvolvimento deste novo remédio custou muito dinheiro ao farmacêutico que, por conta disso, pedia dez vezes mais o valor do custo por uma dose desse remédio. Heinz, o marido da mulher que estava com câncer, procurou as pessoas conhecidas na esperança de obter emprestado o valor pedido pelo farmacêutico. Não conseguindo o valor total, procurou o farmacêutico e contou-lhe sobre sua mulher e pediu-Ihe para vender 0 medicamento mais barato ou que pudesse complementar o valor posteriormente. 0 farmacêutico respondeu que não, que havia desenvolvido o medicamento e que queria ganhar dinheiro com a sua descoberta. Heinz, que tinha feito tudo ao seu alcance para comprar o medicamento, ficou desesperado e planeja assaltar a farmácia.

A questão pode ser sintetizada assim: Heinz deve assaltar a farmácia para roubar o medicamento a fim de salvar a sua mulher? Poderiamos propor os seguintes desdobramentos partindo da suposição de que Heinz assaltasse a farmácia:

- A posição do farmacêutico é correta?

- Deveria o farmacêutico denunciar o roubo?

- Ao ser chamada, a polícia conheceria as motivações de Heinz para o assalto. Deve a polícia acusar Heinz? Supondo que sim, deveria prendê-lo?

- Supondo que ele tenha sido denunciado e preso, ao ser levado ao Tribunal, deve o Juiz condenar Heinz, suspender a pena ou libertá-lo?

Buscando orientar a prática escolar, podemos buscar alguns pontos orientadores indicados por Puig (1999 apud GONÇALVES et al., 2005):

- Definição clara do âmbito do dilema: o dilema precisa ser suficientemente conhecido pelos alunos, podendo referir-se a fatos reais ou imaginários, não devendo conter informações desnecessárias. 
- Definição de um protagonista: os dilemas devem ter sempre protagonistas que experimentam o conflito de valores. Esses devem decidir o que fazer e justificar com argumentos a sua decisão.

- Exigência de uma escolha: o dilema deve propor a escolha entre alternativas conflitivas, que encerram valores em si defensáveis.

- Proposição de temáticas morais: para favorecer o desenvolvimento moral, as temáticas devem possuir conteúdo moral, que tenham em sua base conflitos de interesses individuais e sociais.

- Formulação de questões: deve ser perguntado ao final da narrativa do dilema "o que deveria fazer o protagonista?" e "por que deveria fazer?", centrando-se a discussão na justificativa da decisão considerada correta pelo protagonista.

- Formulação de questões e dilemas alternativos: dilemas alternativos, relacionados com o dilema central podem provocar conflito e convidar à reflexão e à discussão, incentivando a visualizá-lo a partir de outras perspectivas.

Muitas situações críticas reais são equivalentes a essa história e estão presentes no cotidiano. Diniz e Arraes (2001) aplicam este dilema à pesca da lagosta. Outros exemplos são:

- 0 furto de energia em diversas comunidades onde aquele que se beneficia transfere para os demais membros o custo do total da energia consumida;

- As empresas de fertilizante e de agrotóxico que mantêm a fabricação de produtos proibidos nos países onde estão suas matrizes por força de liminares, colocando em risco a saúde da população em geral e dos agricultores em particular;

- 0 cidadão fumante que teima em fumar em lugares sem ventilação, obrigando os demais cidadãos a inalarem a fumaça, em nome de sua liberdade de fumar.

- "Os caçadores de baleias sabiam que outros explorariam as baleias se não o fizessem, e que caçar umas poucas baleias não afetaria a espécie. Daí, a tragédia. 0 interesse de todos (a preservação) não encontrou respaldo no interesse individual" (MYERS, 2000, p. 283).

Outros exemplos e o aprofundamento da técnica de dilemas morais podem ser encontrados em Souza (2008).

\section{Dramatização}

Belmar (2003), estudando os recursos metodológicos possíveis para a redução dos conflitos escolares, propõe a dramatização como alternativa. 0 autor enfatiza que este recurso de ensino permite ao aluno colocar-se no lugar das pessoas, buscando compreender suas posições, argumentos e sentimentos, e adotar perspectivas sociais a partir da representação dos distintos papéis do jogo. 
Para Gonçalves e outros (2005, não paginado)

A dramatização possibilita que os participantes vivenciem os seus conflitos de interação social, liberem tensões e elaborem criativamente novas formas de solução. Na dramatização, a situação é vivenciada como se fosse real, deixando que aflorem emoções, que apareçam conflitos reprimidos e que os participantes se sensibilizem nas relações interpessoais.

Na dramatização, os participantes são ativos, participam com sentimentos e emoções na situação representada. Essa participação certamente é uma forma de produzir mudanças e transformações, fugindo a um verbalismo que procura "aconselhar", definindo "teoricamente" o que é certo ou errado.

É possivel perceber que há grande semelhança entre a fundamentação do autor na defesa da dramatização e aquela apresentada para controvérsia controlada e 0 dilema. Talvez possamos ensaiar algumas diferenças entre essas três técnicas de ensino. A controvérsia talvez se preste a eventos maiores como decisões de impacto social como, por exemplo, a controvérsia sobre a implantação das usinas hidrelétricas no rio Madeira; os dilemas permitem a oportunidade de racionalizar posições pessoais frente a decisões que envolvem valores e sentimentos e, a dramatização permitirá a vivência emocional do fato promotor do conflito. Três maneiras de enfatizar fatos geradores de conflito.

Para Belmar (2003), a dramatização possui quatro fases, a saber:

Fase 1. Treinamento - Criar um clima favorável de confiança e de participação. Animar o grupo a trabalhar o problema que todos aceitaram como um tópico de interesse.

Fase 2. Preparação da dramatização - 0 facilitador apresentará a dramatização a ser executada, indicando claramente qual é o conflito, que personagens intervêm e que cenas serão retratadas. Voluntários são convidados a assumir diferentes personagens, eles têm alguns minutos para preparar a representação. Distribuem-se pautas de observação para os demais alunos da classe (interpretação de papéis e focalização do problema ou da situação escolhida).

Fase 3. Dramatização - Interpretação das personagens principalmente com base no diálogo. Esforço dos "atores" para assumir seu papel e encontrar argumentos para defender a sua posição. 0 facilitador conclui a representação quando acreditar que tenham sido apresentados elementos suficientes para a discussão.

Fase 4. Debate - A análise dos elementos que surgiram na dramatização. Transferência para situações reais dos estudantes. Tentativa de tirar as conclusões 
com o grupo. Consulta ao resto da turma sobre a forma de interpretar e se os atores se colocaram no papel anteriormente propostos. Como viram os diferentes personagens? Surgiram os principais argumentos de cada uma das partes representadas? Como a representação nos ajuda a analisar a situação e esclarecer o problema? Percebemos mais soluções alternativas? Ao final, pergunta-se aos atores como eles se sentiram no papel e o que eles acharam de mais dificil.

0 mesmo autor ainda propõe uma lista de aspectos a serem considerados na elaboração e desenvolvimento da técnica proposta:

1. Tópico:

Concentrar nas necessidades, interesses, desejos ou valores que estão em conflito.

2. Descrição da situação:

2.1. Contextualizar a situação.

2.2. Explicar a história para que se possa intuir a causa da situação de conflito que vai utilizar para a representação dos papéis.

3. Especificão:

3.1. Qual o conflito, situação problemática que se representará.

3.2. Qual é o cenário onde terá lugar.

3.3. Quais são os personagens que fazem intervenções. Descrever suas caracteristicas: personalidade, maneira de pensar e agir.

4. De como dispor o cenário para a dramatização:

4.1. Disposição da aula, das pessoas que representam e as que observam.

4.2. Elementos decorativos que deveriam constar.

5. Escreve quatro ou cinco perguntas que seriam apresentadas ao grupo para o aprofundamento do conflito em estudo, bem como o valor que se vai trabalhar na representação.

Na sequência de seu texto, Belmar (2003) apresenta alguns exemplos de dramatização, tais como: habilidades sociais de comunicação; discriminação estudantil; consumo de drogas na adolescência e conflitos entre pais-filhos

\section{Conclusão}

A violência escolar é o assunto da hora! Dada a relevância e aos repetidos episódios infelizes, consideramos que o assunto esta assumindo posição importante na pauta de prioridades educacionais pelos seus gestores, mais pela solicitação da sociedade que se vê encurralada pelos recorrentes episódios de violência do que pelo compromisso de gestores educacionais para com o restabelecimento do clima escolar como condição indispensável à aprendizagem e ao ensino. Acompanhamos Galvão e outros $(2010$, p. 437) quando escrevem que "a escola é autora, vítima e palco da violência" e Caballero (2000) quando afirma que não é justo 
culpar a escola pelos problemas de violência escolar - da qual é também vítima mas podemos responsabilizar a instituição escolar pelas respostas que dá - ou não - a estes problemas. Nós, os professores e gestores contemporâneos não fomos treinados para conviver e solucionar este tipo de situação-problema, mas precisamos apresentar soluções que modifiquem, mesmo que lentamente, o quadro que se desenha na atualidade.

Se desenvolvido a partir da tese apresentada - de que a escola não está preparada para lidar com a massificação e com a existência de alunos divergentes e diferentes, quer no campo da gestão, quer no campo da relação pessoal, quer no campo da aprendizagem e do ensino -, com a respectiva alternativa - a mediação do conflito como prevenção da violência -, 0 assunto pode sugerir alternativas para a condução do problema na busca de solução possivel e factivel, afastando propostas miraculosas e de difícil entendimento, mas, para isso, é importante que fique claro qual o foco que se pretende dar ao conjunto de ações ou política pública.

As atividades de ensino podem e devem colaborar para que a escola alcance seus reais objetivos: acolher crianças e jovens e acompanhá-los na difícil viagem ao caminho do conhecimento armazenado..., mas também deve oferecer ferramentas para que se faça a viagem interior onde cada se descobre a si mesmo e, por isso, melhor consegue ver e entender o outro que lhe apresenta diferente!

\section{Referências}

BELMAR, A. M. El juego de rol: recurso metodológico para la resolución de conflictos escolares. In: VINYAMATA, E. (Coord.). Aprender del conflicto: conflictologia y educación. Barcelona: Graó, 2003.

CABALLERO, A. Transformar los conflictos: una apuesta. Tarbiya: revista de Investigación e Innovación Educativa, Madrid, n. 25, p. 95-106, 2000.

CARVALHO, W. L. P. et al. Estudo do impacto sócio-ambiental causado pela construção das usinas hidroelétricas da região de llha Solteira. In: PINHO, S. Z.; SAGLIETTI, J. R. C. (Org.). Núcleos de ensino. São Paulo: Ed. Unesp, 2006. Disponivel em: <http://www.unesp.br/prograd/PDFNE2004/artigos/eixo2/ estudoimpactosocioambiental.pdf>. Acesso em: 23 fev. 2011.

CHEMEN, S. Qué puede hacer la escuela com la violência. . In: IMBERTI, J. Violencia y escuela: miradas y propuestas concretas. Buenos Aires: Paidós, 2006.

CHRISPINO, A. Os cenários futuros como consenso social: do contrato social ao universo educacional. RBEP, Brasília, DF, v. 82, n. 200/201/202, p. 40-56, jan./dez. 2001a. 
CHRISPINO, A. Cenários futuros e os cenários em educação: um exemplo aplicado à educação média. Tese (Doutorado em Educação) - Faculdade de Educação, Universidade Federal do Rio de Janeiro, Rio de Janeiro, 2001b.

Os cenários futuros para a educação. Rio de Janeiro: FGV, 2009a.

Ciência, tecnologia e sociedade. Rio de Janeiro: CEFET/RJ, UAB, $2009 \mathrm{~b}$.

Curso de Especialização em Educação Tecnológica: módulo 3.

- Gestão do conflito escolar: da classificação dos conflitos aos modelos de mediação. Ensaio: avaliação e políticas públicas em educação, Rio de Janeiro, v. 15, n. 54, p. 11-28, jan./mar. 2007.

Proibição do fumo: decisão pessoal ou social?. [S. I.]: OEl, 2005. Curso a distância: módulo 6. Disponivel em: <http://www.campus-oei.org/salactsi/ alvaro.htm>. Acesso em: 23 fev. 2011.

CHRISPINO, A.; CHRISPINO, R. S. P. A judicialização das relações escolares e a responsabilidade civil dos educadores. Ensaio: aval. pol. públ. Educ., Rio de Janeiro, v. 16, n. 58, mar. 2008. Disponivel em: <http://www.scielo.br/scielo.php?script=sci_arttextAtpid=S010440362008000100002\&lng=pt¿tnrm=iso> . Acesso em: 19 fev. 2011.

CHRISPINO, A.; CHRISPINO, R. S. P. Políticas educacionais de redução da violência: mediação do conflito escolar. São Paulo: Biruta, 2002.

CHRISPINO, A.; DUSI, M. L. H. M. Uma proposta de modelagem de política pública para a redução da violência escolar e promoção da Cultura da Paz. Ensaio: avaliação e políticas públicas em educação, Rio de Janeiro, v.16, n. 61, p. 597-624, out./dez. 2008.

DINIZ, M. B.; ARRAES, R. A. "Tragédia dos comuns" e o exemplo da pesca da lagosta: abordagens teóricas. Belém, PA, [1999?]. Disponivel em: <http://www.abepro.org.br/ biblioteca/ENEGEP2001_TR60_0114.pdf >. Acesso em: 16 nov. 2008.

ESTEVE, J. M. Mudanças sociais e função docente. In: NÓVOA, A. (Org.). Profissão professor. Porto, PT: Porto, 1995.

FARIAS, C. R. 0.; CARVALHO, W. L. P. 0 direito ambiental na sala de aula: significados de uma prática educativa no ensino médio. Ciência \&t Educação, Bauru, SP, v. 13, n. 2, p. 157-174, 2007.

FIERRO, M. C. Escuelas que construyen respons-habilidad em convivencia escolar. In: FURLÁN, A. et al. (Comp.). Violencia en los centros educativos: conceptos, diagnósticos e intervenciones. Buenos Aires: Noveduc, 2010. 
FLECHSIG, K.-H.; SCHIEFELBEIN, E. (Ed.). 20 Modelos didácticos para América Latina. Washington, D.C.: OEA, 2003. Disponivel em: <http://www.educoas.org/ portal/bdigital/contenido/interamer/interamer_72/SchiefelbeinChapter7New.pdf>. Acesso em: 13 jul. 2008.

FRANKL, V. E. Em busca de sentido: um psicólogo no campo de concentração. Petrópolis: Vozes, 1991.

GALVÃO, A. et al. Violências escolares: implicações para a gestão e o currículo. Ensaio: aval. pol. públ. Educ., Rio de Janeiro, 2010, v. 18, n. 68, p. 425-442, 2010. Disponivel em: <http://www.scielo.br/scielo.php?script=sci_arttext\&tpid=S010440362010000300002 tting=pt\&tnrm=iso $>$. Acesso em: 19 fev. 2011.

GONCALVES, M. A. S. et al. Violência na escola, práticas educativas e formação do professor. Cadernos de Pesquisa, São Paulo, v. 35, n. 126, p. 635-658, 2005. Disponivel em: <http://www.scielo.br/scielo.php?script=sci_arttext\&tpid=S010015742005000300006 tting=enctnrm=iso >. Acesso em: 21 nov. 2008.

HEREDIA, R. A. S. Enfoque global de la escuela como marco de aplicaciona de los programas de resolución de conflitos. In: BRADONI, F. (Comp.). Mediación escolar. Buenos Aires: Paidos, 1999.

IANNI, N. D. La complexa tarea de construir un sistema de convivencia en la escuela. Ensaios y Experiencias: psicología en el campo de la educación, Buenos Aires, n. 35, p. 65-76, 2000.

JAPIASSÚ, H.; MARCONDES, D. Dicionário básico de filosofia. Rio de Janeiro: Jorge Zahar, 1996.

JOHNSON, D. W.; JOHNSON, R. T. Como reducir la violencia en las escuelas. Buenos Aires: Paidós, 2004.

LIPMAN, M.; SHARP, A. M.; OSCANYAN, F. S. La filosofía en el aula. Madrid: Ed. de la Torre, 1992.

MíGUEZ, D. (Comp.).Violencias y conflitos em lãs escuelas: aproximaciones a uma problemática actual. Buenos Aires: Paidós, 2008.

MORA, J. F. Dicionário de filosofia. São Paulo: Martins Fontes, 1993.

MYERS, D. G. Psicologia social. Rio de janeiro: LTC, 2000. 
NATO, A. M.; QUEREJAZU, M. G. R.; CARBAJAL, L. M. Mediación comunitária: conflictos em el escenário social urbano. Buenos Aires: Editorial Universidad, 2006.

ONETTO, F. Climas educativos y prognósticos de violência: condiciones institucionales de la convivência escolar. Buenos Aires: Ediciones Novedades Educativas, 2004.

POLAK, F. L. The image of the future. Amsterdam: Elsevier Scientificn Publishing Co., 1961.

REIS, P. R. A escola e as controvérsias sociocientificas: perspectivas de alunos e professores. Lisboa: Escolar Ed., 2008.

SCHVARSTEIN, L. La mediación escolar em contexto. In: BRADONI, F. (Comp.). Mediación escolar. Buenos Aires: Paidos, 1999.

SINGER, B. D. The future focused role image. In: TOFFLER, A. (Org.). Learning for tomorrow. Westminster, MD: Random House, 1974.

SOUZA, L. K. 0 debate de dilemas morais na universidade. Psicol. esc. educ., Campinas, SP, v. 12, n. 1, p. 169-183, 2008. Disponivel em: <http://www.scielo.br/pdf/pee/v12n1/v12n1a12.pdf>. Acesso em: 21 nov. 2008.

ZEHR, H. Trocando as lentes: um novo foco sobre o crime e a justiça. São Paulo: Palas Athena, 2008.

Recebido em: 29/11/2010

Aceito para Publicação em: 14/02/2011 